\title{
Plasma Microparticle Tissue Factor Activity in Patients With Antiphospholipid Antibodies With and Without Clinical Complications
}

\author{
Rose Willemze, Robert L. Bradford ${ }^{\star}$, Micah J. Mooberry ${ }^{\star}$, Robert A. S. Roubey ${ }^{\star}$, and Nigel S. \\ Key
}

University of Groningen School of Medicine, Netherlands *Department of Medicine, University of North Carolina at Chapel Hill, USA

\begin{abstract}
Antiphospholipid syndrome (APS) is defined by the association of autoantibodies to certain phospholipid-binding proteins with arterial or venous thrombosis ('AT' or 'VT', respectively), and/or pregnancy-related morbidity (PM). Antiphospholipid antibodies (aPLA) promote activation of several cell types including monocytes, resulting in procoagulant tissue factor (TF) expression that may contribute to the vascular complications. Since TF synthesis by monocytes is frequently accompanied by release of TF-bearing microparticles, we hypothesized that plasma microparticle TF activity (MP-TF) may be elevated in APS patients and contribute to thrombosis and/or PM. Platelet-poor plasma specimens were obtained from 30 patients with definite APS and 72 patients with asymptomatic aPLA from the Antiphospholipid Syndrome Collaborative Registry (APSCORE). MP-TF was measured by an in-house factor Xa generation assay. The two groups were well matched for gender, age, ethnicity, proportions with underlying SLE, and aPLA profiles. MP-TF (median and (IQR)) in asymptomatic aPLA subjects was $0.09 \mathrm{pg} / \mathrm{mL}(0.05-0.14)$ compared to $0.13 \mathrm{pg} / \mathrm{mL}(0.10-0.17)$ in APS $(\mathrm{p}<0.001)$. No differences in MP-TF levels were observed between APS subjects with PM, thrombosis, or PM + thrombosis. Similarly, among subjects with either APS or asymptomatic aPLA, MP-TF did not differ in the presence or absence of underlying SLE. Prospective studies will be required to determine if plasma MP-TF activity is causally related to thrombotic or gestational complications in APS.
\end{abstract}

\section{Keywords}

Microparticle; tissue factor; antiphospholipid syndrome; thrombosis; pregnancy

\section{(C) 2013 Elsevier Ltd. All rights reserved.}

Address correspondence to: Nigel S. Key, MB, ChB, FRCP, Harold R. Roberts Distinguished Professor of Medicine and Pathology and Laboratory Medicine, 303 Mary Ellen Jones Building, CB \#7035, Chapel Hill, NC 27599, USA, Tel: 919-966-3311, Fax: 919-966-7639,nigel_key@med.unc.edu.

Statement of conflicts of interest: None of the authors has any conflict of interest to report

Publisher's Disclaimer: This is a PDF file of an unedited manuscript that has been accepted for publication. As a service to our customers we are providing this early version of the manuscript. The manuscript will undergo copyediting, typesetting, and review of the resulting proof before it is published in its final citable form. Please note that during the production process errors may be discovered which could affect the content, and all legal disclaimers that apply to the journal pertain. 


\section{Introduction}

Antiphospholipid syndrome (APS) is a term used to describe the association of autoantibodies directed against phospholipid-binding proteins with adverse clinical outcomes such as AT or VT, or pregnancy-related morbidity PM ${ }^{1}$. International consensus classification criteria for definite APS were first published in 1999 and subsequently revised in $2006^{2}$.

It is also apparent that aPLA may be incidentally detected in a small proportion of the healthy population. These individuals may be at increased risk of thrombosis compared to the general population ${ }^{3}$. However, given that many subjects with persistent aPLA remain asymptomatic, prognostic markers capable of estimating the individual risk of developing thrombosis would be of potentially great utility.

Tissue factor (TF) is a transmembrane glycoprotein that in complex with factor VII(a) initiates coagulation and is essential for haemostasis. There is growing evidence that aberrant TF expression plays a role in the thrombotic and vascular events in patients with $\mathrm{APS}^{1,3-7}$. It has been shown that TF synthesis in monocytes and endothelial cells is induced by aPLA in vitro ${ }^{7,8}$. Other stimuli (such as LPS, oxidized LDL and the platelet factor 4heparin-antibody complex) that activate monocytes resulting in TF expression also induce the release of TF-bearing microparticles (MP-TF), both in vitro and in vivo ${ }^{9}$. Circulating microparticles are sub-micron sized cellular fragments that may support physiological hemostasis and/or promote pathological thrombosis. Microparticle activation of coagulation may be TF-dependent or TF-independent, the latter via assembly of coagulation enzymatic complexes on the microparticle surface where anionic phospholipids are abnormally displayed ${ }^{9}$.

In this study, we measured MP-TF activity in plasma samples from patients with APS and asymptomatic aPLA to test the hypothesis that MP-TF activity levels are higher in APS compared to subjects with aPLA without clinical manifestations.

\section{Material and Methods}

\section{Study subjects}

The subjects for this study were a subset of subjects from the Antiphospholipid Syndrome Collaborative Registry (APSCORE) (ClinicalTrials.gov:NCT00076713). Samples were collected between 2002 and 2007. All subjects met serological criteria for definite APS based on international consensus criteria ${ }^{2}$. Participants included those who met clinical criteria for definite APS as well as asymptomatic subjects with aPLA but without clinical manifestations of APS. In addition, subjects included individuals with and without underlying systemic lupus erythematosus (SLE) or other autoimmune diseases. APS cases were defined as individuals meeting both clinical and serological criteria for definite APS ${ }^{2}$. Neither subjects with APS nor controls with aPLA were taking warfarin or heparin at enrollment.

\section{Blood collection and sample preparation}

Blood was collected in citrate-anticoagulated tubes by venipuncture using standard sterile technique. All samples were processed within 4 hours of collection. Blood was centrifuged at $1,500 \times \mathrm{g}$ for 10 minutes at $4^{\circ} \mathrm{C}$. The platelet poor plasma was carefully removed into microcentrifuge tubes, taking care not to disturb the buffy coat layer. A second centrifugation was performed at $2,000 \times \mathrm{g}$ for 5 minutes to obtain platelet free plasma, defined as $<2,000 \times 10^{9}$ platelets $/ \mathrm{L}$. Plasma aliquots of $200 \mu \mathrm{L}$ were stored at $-80{ }^{\circ} \mathrm{C}$. Samples were thawed in a water bath at $37^{\circ} \mathrm{C}$ prior to use. 


\section{Microparticle tissue factor (MPTF) activity assay}

A previously described kinetic assay was employed to measure MP-TF activity on the platelet free (PFP) plasma samples ${ }^{10,11}$. Briefly, microparticles (MP) were isolated from plasma via high speed centrifugation $\left(20,000 \mathrm{~g}\right.$ for 30 minutes at $\left.4^{\circ} \mathrm{C}\right)$. The MP pellet was resuspended in buffer via mild sonication and incubated with human Factor X, VIIa, and $\mathrm{Ca}^{2+}$ in the presence and absence of a tissue factor blocking antibody. After the addition EDTA and FXa chromogenic substrate, absorbance measurements were made over time and related to an Innovin ${ }^{\mathrm{TM}}$ standard to calculate MP-TF activity.

\section{Statistics}

For comparison between the APS and the aPLA groups, a one-tailed Mann Whitney Test was performed. A Kruskal-Wallis test was used to compare the APS subgroups. A linear regression was performed to calculate the $\mathrm{R}^{2}$ to correlate the laboratory values and the MPTF activity. All analyses were performed using Graphpad Prism version 5.0 for Windows. (Graphpad Software, San Diego California, USA). Statistical significance was defined by $\mathrm{p}$ $<0.05$.

\section{Results}

\section{Study subject clinical and laboratory features}

As shown in Table 1, patient groups were well matched for age, ethnicity, and whether underlying SLE was present or not. As expected, the majority of subjects were female. The aPLA laboratory data are illustrated in Table 1 . Among the group with APS, 8 subjects had experienced VT (including 1 subject with 2 events), 7 had experienced AT (including 3 with 2 events each), and 7 had experienced PM. Three additional subjects had suffered PM and a single VT, 4 had experienced PM and a single AT, and 1 subject had suffered PM in addition to $1 \mathrm{VT}$ and $2 \mathrm{AT}$ events [Table 2].

\section{MP-TF activity in subjects with aPLA compared to patients with APS}

Plasma MP-TF activity in patients with APS was significantly higher compared to subjects with asymptomatic aPLA $(\mathrm{p}<0.001)$ [Figure 1A]. However, a considerable degree of overlap between the groups was apparent. Since the test samples were collected at various times following the thrombotic or pregnancy-related event in patients with APS, we were unable to determine whether any heterogeneity in MP-TF activity could be explained by temporal proximity to the index event. MP-TF activity did not demonstrate any difference between the APS sub-groups with thrombosis (median (IQR)): $0.12 \mathrm{pg} / \mathrm{mL}(0.08-0.17)$ ), pregnancyrelated morbidity $(0.16 \mathrm{pg} / \mathrm{mL}(0.11-0.17))$ or both $(0.14 \mathrm{pg} / \mathrm{mL}(0.05-0.19))(\mathrm{p}=0.5865$ by Kruskal-Wallis test). Also of note, MP-TF activity in the subgroup of aPLA with a diagnosis of SLE (median (IQR): $0.09 \mathrm{pg} / \mathrm{mL}(0.05-0.13)$ ) was not statistically different compared to the aPLA subgroup without SLE (median (IQR): $0.09 \mathrm{pg} / \mathrm{mL}(0.06-0.14))(\mathrm{p}=0.4871)$ [Figure 1B]. Furthermore, there was no difference in MP-TF activity in the 12 subjects with more than one clinical event (multiple VT, AT or PM or any combination of these events) compared to the MP-TF activity in the 11 subjects with only a single event $(\mathrm{p}=0.5224)$.

\section{Correlation between laboratory values and MP-TF activity}

The correlation between the aPLA laboratory values (IgG and IgM anti-cardiolipin antibodies and lupus anticoagulant (LAC)) and the MP-TF activity was assessed using linear regression. There was no significant correlation between MP-TF and any form of aPLA ( $\mathrm{R}^{2}$ $<0.02)$. 


\section{Discussion}

This cross-sectional study examined MP-TF activity in subjects with elevated aPLA with and without clinical manifestations of APS. Anti-phospholipid antibodies are generally recognized to be a risk marker for venous or arterial thrombosis, as well for morbidity during pregnancy ${ }^{1,3}$. A variety of pathologic mechanisms have been proposed to account for these complications, including the activation of monocytes and endothelial cells, leading to de novo synthesis of $\mathrm{TF}^{1,3,13}$. Since $\mathrm{TF}$ synthesis during monocyte activation is generally coupled to the generation of TF-bearing microparticles, we hypothesized that MP-TF levels would be more elevated in subjects with a history of clinical complications (i.e. APS) compared to asymptomatic subjects with persistent aPLA only. This hypothesis proved to be correct, albeit with significant overlap between subjects and controls. Similar degrees of overlap have however been observed in studies of similar design comparing cancer patients with and without thrombosis, where the role of MP-TF is currently under active investigation ${ }^{14}$. In this study, we did not observe any difference in MP-TF levels between APS subjects according to the type of clinical complication (thrombosis or PM), nor whether underlying SLE was present or not in subjects with aPLA.

This study has several limitations. First, we used samples that were collected up to 10 years previously. Although an effect of prolonged storage on the levels of MP-TF cannot be excluded, we, and others have observed that most assays for microparticles are relatively unaffected by storage ${ }^{10,11,14}$. Specifically, the measured values of MP-TF in normal and abnormal controls used for internal quality control have shown stable levels over at least 3 years (unpublished data). Although no similarly long-term stored samples from healthy controls were available for side-by-side comparison in this study, the measured MP-TF values are comparable to the usually observed range in our laboratory ${ }^{10,13}$. Second, we did not have adequate available samples to determine the cellular source of the TF-expressing MPs, nor whether APS was associated with an increase in MP from multiple cellular sources, or merely from monocytes or endothelial cells only. Such analysis is generally performed by flow cytometry, although this technique has its own inherent limitations, including the inability to enumerate or characterize microparticles with a size below about $0.5 \mu \mathrm{m}^{9,11,14}$. In this respect, a functional assay for MP-TF, such as the one used here, has no theoretical lower size limitations ${ }^{11}$. Third, we did not investigate the potential mechanism(s) of monocyte TF induction and vesiculation, although others have shown that annexin II or the toll-like receptor 4 (TLR4) may be surface receptors responsible for monocyte activation in response to aPLA ${ }^{4,6,7,12}$. Finally, this study is retrospective with all the usual limitations. In particular, we are unable to conclude whether a higher level of MPTF is a cause or the result of thrombosis or pregnancy complications in patients with aPLA. Further prospective studies will be required to determine whether MP-TF is a true prognostic biomarker of the clinical complications that may ensue in patients with aPLA.

\section{Acknowledgments}

The authors wish to thank Dr. Mac Monroe for his helpful suggestions in reference to this study. MJM was supported by NIH grant T32 HL007149.

\section{References}

1. Giannakopoulos B, Krilis SA. The pathogenesis of the antiphospholipid syndrome. The New England journal of medicine. 2013; 368:1033-1044. [PubMed: 23484830]

2. Miyakis S, Lockshin MD, Atsumi T, Branch DW, Brey RL, Cervera R, Derksen RH, PGDEG, Koike T, Meroni PL, Reber G, Shoenfeld Y, Tincani A, Vlachoyiannopoulos PG, Krilis SA. International consensus statement on an update of the classification criteria for definite 
antiphospholipid syndrome (APS). Journal of thrombosis and haemostasis : JTH. 2006; 4:295-306. [PubMed: 16420554]

3. Ruiz-Irastorza G, Crowther M, Branch W, Khamashta MA. Antiphospholipid syndrome. Lancet. 2010; 376:1498-1509. [PubMed: 20822807]

4. Amengual O, Atsumi T, Khamashta MA, Hughes GR. The role of the tissue factor pathway in the hypercoagulable state in patients with the antiphospholipid syndrome. Thrombosis and haemostasis. 1998; 79:276-281. [PubMed: 9493575]

5. Atsumi T, Khamashta MA, Amengual O, Hughes GR. Up-regulated tissue factor expression in antiphospholipid syndrome. Thrombosis and haemostasis. 1997; 77:222-223. [PubMed: 9031483]

6. Sorice M, Longo A, Capozzi A, Garofalo T, Misasi R, Alessandri C, Conti F, Buttari B, Rigano R, Ortona E, Valesini G. Anti-beta2-glycoprotein I antibodies induce monocyte release of tumor necrosis factor alpha and tissue factor by signal transduction pathways involving lipid rafts. Arthritis and rheumatism. 2007; 56:2687-2697. [PubMed: 17665396]

7. Zhou H, Wolberg AS, Roubey RA. Characterization of monocyte tissue factor activity induced by IgG antiphospholipid antibodies and inhibition by dilazep. Blood. 2004; 104:2353-2358. [PubMed: 15226179]

8. Combes V, Simon AC, Grau GE, Arnoux D, Camoin L, Sabatier F, Mutin M, Sanmarco M, Sampol J, Dignat-George F. In vitro generation of endothelial microparticles and possible prothrombotic activity in patients with lupus anticoagulant. The Journal of clinical investigation. 1999; 104:93102. [PubMed: 10393703]

9. Owens AP 3rd, Mackman N. Microparticles in hemostasis and thrombosis. Circulation research. 2011; 108:1284-1297. [PubMed: 21566224]

10. Stravitz RT, Bowling R, Bradford RL, Key NS, Glover S, Thacker LR, Gabriel DA. Role of procoagulant microparticles in mediating complications and outcome of acute liver injury/Acute liver failure. Hepatology. 2013

11. Key NS, Mackman N. Tissue factor and its measurement in whole blood, plasma, and microparticles. Seminars in thrombosis and hemostasis. 2010; 36:865-875. [PubMed: 21049387]

12. Boles J, Mackman N. Role of tissue factor in thrombosis in antiphospholipid antibody syndrome. Lupus. 2010; 19:370-378. [PubMed: 20353972]

13. Manly DA, Wang J, Glover SL, Kasthuri R, Liebman HA, Key NS, Mackman N. Increased microparticle tissue factor activity in cancer patients with Venous Thromboembolism. Thrombosis research. 2010; 125:511-512. [PubMed: 19854471]

14. Lacroix R, Robert S, Poncelet P, Kasthuri RS, Key NS, Dignat-George F. Standardization of platelet-derived microparticle enumeration by flow cytometry with calibrated beads: results of the International Society on Thrombosis and Haemostasis SSC Collaborative workshop. Journal of thrombosis and haemostasis : JTH. 2010; 8:2571-2574. [PubMed: 20831623] 


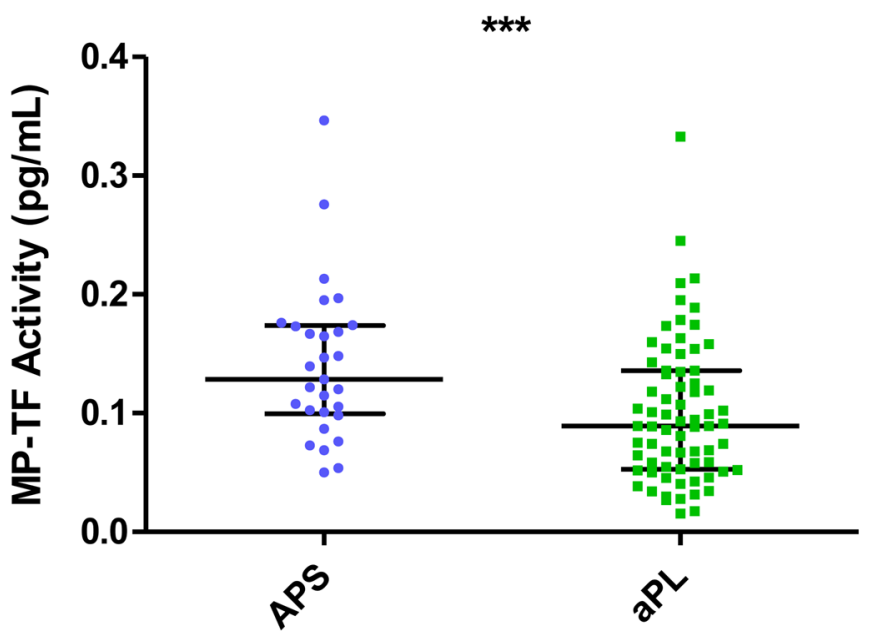

Figure 1A

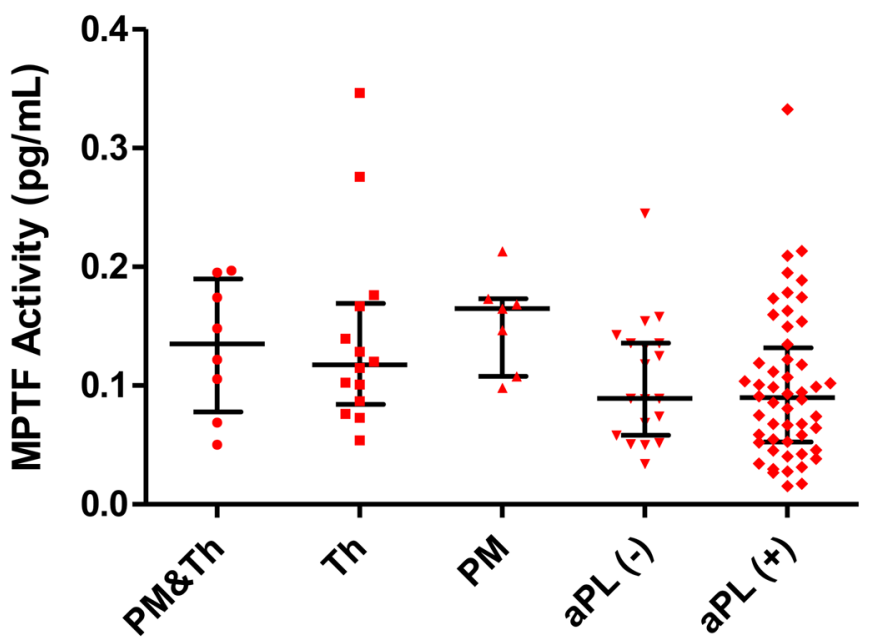

Figure 1B

Figure 1.

Figure 1A: MP-TF activity in subjects with anti-phospholipid syndrome (APS) and control subjects with asymptomatic anti-phospholipid antibodies (APL). Data are presented as medians and inter-quartile ranges. [***p<0.001].

Figure 1B: MP-TF activity according to sub-groups. Data are presented as medians and inter-quartile ranges. Abbreviations: $\mathrm{Th}=$ history of thrombosis; $\mathrm{PM}=$ history of pregnancyrelated morbidity; aPL $(-)=$ asymptomatic with antiphospholipid antibodies but without SLE; aPL (+) = asymptomatic with antiphospholipid antibodies and SLE. 
Table 1

Demographic features

\begin{tabular}{|l|c|c|}
\hline & Subjects with APS (N = 30) & Subjects with aPL (N = 72) \\
\hline Gender & & \\
\hline Male & $3(10.0 \%)$ & $11(15.3 \%)$ \\
\hline Female & $27(90.0 \%)$ & $61(84.7 \%)$ \\
\hline Ethnic group ${ }^{*}$ & & \\
\hline Caucasian & $22(73.3 \%)$ & $50(69.4 \%)$ \\
\hline Afro-American & $5(16.7 \%)$ & $13(18.1 \%)$ \\
\hline Hispanic & $2(6.7 \%)$ & $4(5.6 \%)$ \\
\hline Others & $1(3.3 \%)$ & $4(5.6 \%)$ \\
\hline Mean age & $46.7( \pm 12.0)$ & $47.7( \pm 12.0)$ \\
\hline Primary APS/aPL & $11(33.3 \%)$ & $19(26.4 \%)$ \\
\hline APS/aPL secondary to SLE & $19(63.3 \%)$ & $53(73.6 \%)$ \\
\hline Elevated IgG (aCL) & $12(40.0 \%)$ & $21(29.2 \%)$ \\
\hline Elevated IgM (aCL) & $5(16.7 \%)$ & $22(30.6 \%)$ \\
\hline Positive LAC & $18(60.0 \%)$ & $46(63.9 \%)$ \\
\hline Median IgG & $42 \pm 5.5-69.5$ & $15.8 \pm 4.4-73.9$ \\
\hline Median IgM & $21.8 \pm 4.1-64.9$ & $24.5 \pm 5.4-66.5$ \\
\hline
\end{tabular}

APS $=$ antiphospholipid antibody syndrome

$\mathrm{aPL}=$ antiphospholipid antibodies

SLE $=$ systemic lupus erythematosus

$\mathrm{aCL}=$ anticardiolipin antibodies

LAC $=$ lupus anticoagulant

Ethnicity of 1 subject with aPL is unknown.

4 subjects with symptomatic APS and 6 subjects with asymptomatic APS had more than one elevated or positive marker.

In the subjects with symptomatic APS: 7 subjects had missing aCL values. 1 subject had only one value of IgG. 3 subjects had only one value of IgM. 3 subjects had only one value of both IgG and IgM. 4 subjects had only one value of LAC.

In the subjects with asymptomatic APS: 2 subjects had missing aCL values. 1 subject had missing LAC values. 1 subject had only one value of IgM. 4 subjects had only one value of LAC. 
Table 2

Clinical manifestations in subjects with APS

\begin{tabular}{|c|c|}
\hline & Number of Subjects \\
\hline Venous Thrombosis (VT) & \\
\hline One Event & 7 \\
\hline Two Events & 1 \\
\hline Arterial Thrombosis (AT) & \\
\hline One Event & 4 \\
\hline Two Events & 3 \\
\hline Pregnancy Morbidity (PM) & 7 \\
\hline PM \& one VT & 3 \\
\hline PM \& one AT & 4 \\
\hline PM \& 2 AT \& 1 VT & 1 \\
\hline
\end{tabular}

